\title{
Elucidating Antibacterial Activity and Mechanism of Daphnetin against Pseudomonas fluorescens and Shewanella putrefaciens
}

\author{
Wenru Liu, ${ }^{1}$ Jun Mei $\mathbb{D}^{1,2,3,4}$ and Jing Xie $\mathbb{D}^{1,2,3,4}$ \\ ${ }^{1}$ College of Food Science and Technology, Shanghai Ocean University, Shanghai 201306, China \\ ${ }^{2}$ National Experimental Teaching Demonstration Center for Food Science and Engineering, Shanghai Ocean University, \\ Shanghai 201306, China \\ ${ }^{3}$ Shanghai Engineering Research Center of Aquatic Product Processing and Preservation, Shanghai 201306, China \\ ${ }^{4}$ Shanghai Professional Technology Service Platform on Cold Chain Equipment Performance and Energy Saving Evaluation, \\ Shanghai 201306, China
}

Correspondence should be addressed to Jun Mei; delightmay@hotmail.com and Jing Xie; jxie@shou.edu.cn

Received 7 October 2020; Revised 19 October 2020; Accepted 31 October 2020; Published 19 November 2020

Academic Editor: Muhammad H. Alu'datt

Copyright (c) 2020 Wenru Liu et al. This is an open access article distributed under the Creative Commons Attribution License, which permits unrestricted use, distribution, and reproduction in any medium, provided the original work is properly cited.

In this research, the antibacterial activity and mechanism of daphnetin against Pseudomonas fluorescens and Shewanella putrefaciens were evaluated. The minimum inhibitory concentration (MIC) of daphnetin on P. fluorescens and S. putrefaciens was 0.16 and $0.08 \mathrm{mg} \cdot \mathrm{mL}^{-1}$, respectively. The growth curve test also showed that daphnetin had a good antibacterial effect. The results of intracellular component leakage and cell viability analysis illustrated that daphnetin destroyed the morphology of the cell membrane. According to scanning electron microscope and transmission electron microscope observations, the treated bacterial cells displayed obvious morphological and ultrastructural changes in the cell membrane of the two tested strains, whichconfirmed daphnetin's damage to the integrity of the cell membrane. The findings indicated that daphnetin mainly exerted its antibacterial effect by destroying the membrane and suggested that it had good potential to be as a natural food preservative.

\section{Introduction}

Fish is a nutritious food source and is recommended because of its multiple nutritional values [1]. It is low in saturated fats and rich in poly-unsaturated fatty acids (PUFA) and protein. It also contains many other healthy nutrients, such as selenium, iodine, and vitamin D [2]. The World Health Organization (WHO) suggests eating 1-2 servings of fish regularly each week to provide an equivalent of $200-500 \mathrm{mg}$ of omega-3-PUFA [3].

However, the quality of fresh fish can easily deteriorate after being slaughtered. Most fish are degraded by digestive enzymes and lipases, microbial spoilage, and oxidation of surface bacteria [4]. P. fluorescens and S. putrefaciens are Gram-negative bacteria and considered to be specific spoilage organisms (SSOs) that are common during refrigeration of fish and fish products [5-7]. Furthermore, changes in the composition of fish during decay not only lead to lipid oxidation and protein degradation but also the loss of other valuable molecules. What's more, high-quality and less processed products are increasingly demanded by consumers. The soft or mushy texture of fish will affect the shelf life and thus hinder the sale of the product. Therefore, fish are traditionally cooled and stored in flake ice, frozen seawater, or ice slurry, and some are even preserved by exposure to chemical agents $[8,9]$.

In recent years, researchers have made considerable efforts to find natural preservatives in order to slow or inhibit bacteria and fungi growth in fish. Meanwhile, an increasing number of consumers are conscious of the potential negative health effects of synthetic preservatives and the benefits of natural additives, which prompt food industry to 
seek natural products as alternatives. Many preservatives derived from plants have been shown to have antioxidant or antibacterial properties. Daphnetin (7,8-dihydroxycoumarin) is a dihydroxylated derivative of coumarin derived from plants [10] (structure is shown in Figure 1). It is an active element of plant extracted from Daphne Korean Nakai [11], which has been reported to possess antimicrobial, antioxidant, antimalarial, anticoagulation, and immunomodulating activity [12-15]. However, the potential effects of daphnetin on food-borne spoilage bacteria were rarely reported.

Therefore, P. fluorescens and S. putrefaciens, as the SSOs in fish and fish products, were selected as targeted bacteria to evaluate the antibacterial activity and effect mechanism of daphnetin on vegetative cells to provide a basis for daphnetin to replace chemical preservatives in the food industry.

\section{Materials and Methods}

2.1. Chemicals and Bacterial Culture. Daphnetin (HPLC grade, $>90.0 \%)$ was purchased from Tokyo Chemical Industry Co., Ltd (Tokyo, Japan). The prepared P. fluorescens (ATCC 13525) and S. putrefaciens (ATCC 8071) $\left(10^{8}-10^{9} \mathrm{CFU} \cdot \mathrm{mL}^{-1}\right.$, respectively) were, respectively, inoculated into BHI and TSB media (HopeBio, Qingdao) with $1 \%$ inoculation amount and were cultured at $30^{\circ} \mathrm{C}$ for $14 \mathrm{~h}$ and normalized to $\mathrm{OD}_{595}=0.3$. Daphnetin was proportionally dissolved in 3\% dimethyl sulfoxide (DMSO), followed by ultrasonic treatment for $30 \mathrm{~min}$ until complete dissolution.

\subsection{Determination of Minimum Inhibitory Concentration} (MIC) and Minimum Bactericidal Concentration (MBC). Broth microdilution method was used to detect the antimicrobial effect of daphnetin on $P$. fluorescens and $S$. putrefaciens. The test bacterial suspension $\left(10^{5} \mathrm{CFU} \cdot \mathrm{mL}^{-1}\right)$ was mixed with daphnetin $\left(0.01-1.28 \mathrm{mg} \cdot \mathrm{mL}^{-1}\right)$ and cultured with shaking at $30^{\circ} \mathrm{C}$ for $24 \mathrm{~h}$. The minimum concentration of daphnetin added which inhibits the growth of visible bacteria is defined as MIC. In addition, the bacterial suspensions of the test groups without visible bacteria growth were subcultured on nutrient agar to determine that the minimum concentration of daphnetin was defined as $\mathrm{MBC}$, which resulted in no colony growth at all [16].

2.3. Determination of Growth Curve. The growth curves in medium at $30^{\circ} \mathrm{C}$ were determined as previously described [17]. Bacteria were grown to an $\mathrm{OD}_{595}$ value of 0.1 in medium, and then, $150 \mathrm{~L}$ of the culture was transferred into each well of a 100-well microtiter plate (Bioscreen, Finland). The bacterial suspensions were mixed with $1 \times, 2 \times$, and $4 \times$ MIC daphnetin, respectively. $0 \times$ MIC was used as a control. Bacteria were further cultured at $30^{\circ} \mathrm{C}$, and cell growth was monitored at $600 \mathrm{~nm}$ using an automatic microbial growth curve analyzer (Bioscreen C MBR, Bioscreen, Finland). The growth curve was drawn with time as the abscissa and $\mathrm{OD}_{600}$ as the ordinate.<smiles>O=c1ccc2ccc(O)c(O)c2o1</smiles>

Figure 1: Structure of daphnetin.

2.4. Integrity of P. fluorescens and S. putrefaciens Cells and Spores. The integrity of cell membranes can be assessed by detecting the leakage of nucleic acids and proteins in the cells [18]. The steps were as follows: the bacterial suspensions were treated by daphnetin at the concentration of $0 \times, 1 \times$, $2 \times$, and $4 \times$ MIC daphnetin at $30^{\circ} \mathrm{C}$ for $4 \mathrm{~h}$, respectively. After treatment, the bacterial solution was centrifuged ( 3000 $\mathrm{r} / \mathrm{min}, 4^{\circ} \mathrm{C}, 10 \mathrm{~min}$ ) to obtain the supernatant and then filtered through a $0.22 \mu \mathrm{m}$ filter. The amount of nucleic acids and proteins leaking from the cytoplasm was determined by measuring the absorbance readings of the filtrate at $260 \mathrm{~nm}$ and $595 \mathrm{~nm}$ with a UV spectrophotometer (UV-2100, UNICO Instrument Co., Ltd, Shanghai, China). The control group was a $0 \times$ MIC sample.

2.5. Determination of Protein Concentration. The concentration of intracellular protein was obtained by the bicinchoninic acid (BCA) protein assay kit (Jiancheng Bioengineering Institute, Jiangsu, China) absorbance at $562 \mathrm{~nm}$ with a UV spectrophotometer [19].

2.6. Leakage of Intracellular Constituents. Different concentrations of daphnetin were added to the bacterial culture so that the final concentrations were $1 \times, 2 \times$, and $4 \times$ MIC, respectively. A control group $(0 \times \mathrm{MIC})$ was established at the same time. The ATPase activity was determined by the ATPase assay kit (Jiancheng Bioengineering Institute, Jiangsu, China) after $4 \mathrm{~h}$, and the absorbance at $636 \mathrm{~nm}$ was recorded using Microplate Reader (iMark, BIO-RAD, US) [20].

2.7. Integrity of Cell Wall Assays. The prepared bacteria were treated with different concentrations of daphnetin for $4 \mathrm{~h}$ at $30^{\circ} \mathrm{C}$. Then, the AKP assay kit (Jiancheng Bioengineering Institute, Jiangsu, China) was used to measure the activity of alkaline phosphatase (AKP). The absorption value of the supernatant was determined by Microplate Reader at $490 \mathrm{~nm}[21]$.

2.8. Scanning Electron Microscope (SEM) Analysis. Daphnetin with different concentrations was added to the initial suspension. Then, it was cultured with shaking at $30^{\circ} \mathrm{C}$ for $6 \mathrm{~h}$, and then, the bacteria cells were obtained by centrifugation. The samples were fixed with $2.5 \%$ glutaraldehyde solution for $4 \mathrm{~h}$ and washed with $0.01 \mathrm{~mol} / \mathrm{L}$ PBS solution. Then, they were eluted once with $30-90 \%$ ethanol solution and eluted twice with $100 \%$ ethanol solution. The samples were air-dried on the coverslip, sprayed with gold, and observed by using scanning electron microscope (Tescan 
Mira $3 \mathrm{MH}$, TESCAN, Czech Republic). The accelerating voltage was $3 \mathrm{KV}$ [22].

\subsection{Transmission Electron Microscopy (TEM) Analysis.} The control and treated samples were collected and fixed with $2.5 \%(\mathrm{~m} / \mathrm{v})$ glutaraldehyde, washed with $0.01 \mathrm{~mol} / \mathrm{L}$ phosphate buffer, postfixed in $1 \%$ osmium tetroxide, washed with the buffer, continuously dehydrated with ethanol (30, $50,70,80,90,95$, and $100 \%(\mathrm{v} / \mathrm{v}))$, and then treated with pure acetone for $20 \mathrm{~min}$. The samples were embedded with epoxy resin (SPURR) for polymerization and then sliced into thin slices with an ultramicrotome (EMUC7, Leica Microsystems GMBH, Germany). Double staining was done with uranyl acetate and lead citrate. TEM images were obtained using a JEM-2100 TEM (JEOL Ltd., Japan) [23].

2.10. FTIR Spectroscopic Analysis. The prepared bacterial suspension was added into the daphnetin solution with a concentration of $0 \times, 1 \times, 2 \times$, and $4 \times$ MIC daphnetin, respectively. Subsequently, the culture was shaken at $30^{\circ} \mathrm{C}$ for $4 \mathrm{~h}$, and the bacteria were then collected by centrifugation at $3000 \mathrm{rpm}$ for $10 \mathrm{~min}$. The obtained bacterial samples were washed three times with PBS, freeze-dried for $48 \mathrm{~h}$, and then tested with a Fourier infrared spectrometer (Nicolet is 5, Thermo Fisher, USA) [24].

2.11. Statistical Analysis. The experimental results were reported as means \pm SD and statistically analyzed by SPSS 22.0 software. The one-way ANOVA procedure and Duncan's multiple range tests were used to determine significant differences $(p<0.05)$ between mean values of treatments.

\section{Results and Discussion}

3.1. Antibacterial Activity of Daphnetin. The antibacterial activity of daphnetin was evaluated by MIC and MBC values. The MIC of daphnetin against $P$. fluorescens and S. putrefaciens cells was 0.16 and $0.08 \mathrm{mg} \cdot \mathrm{mL}^{-1}$, respectively. The MBC of daphnetin against the two tested strains was $0.16 \mathrm{mg} \cdot \mathrm{mL}^{-1}$. The results of Yang et al. [25] showed that the MIC and MBC of daphnetin anti-R. solanacearum were both $0.064 \mathrm{mg} \cdot \mathrm{mL}^{-1}$, which were slightly lower than those tested in the present study. The results indicated that daphnetin had a good antibacterial effect on $P$. fluorescens and S. putrefaciens.

The growth of the two test bacteria in the presence of different concentrations of daphnetin was plotted to further analyse the antibacterial activity of daphnetin. As shown in Figure 2(a), the growth of bacteria in the control group was consistent with the $S$-shaped growth curve. $P$. fluorescens grew rapidly in the absence of daphnetin and began to enter the exponential phage after $6 \mathrm{~h}$ and then entered the stationary phase after $26 \mathrm{~h}$. However, the groups treated with daphnetin at $1 \times, 2 \times$, and $4 \times$ MIC concentrations completely inhibited the growth of bacteria. S. putrefaciens (Figure 2(b)) without daphnetin addition began to be at an exponential phase after $14 \mathrm{~h}$ and then stationary phase after
$28 \mathrm{~h}$. The growth rate of $S$. putrefaciens with the addition of $1 \times$ MIC daphnetin was slower than that of the control. The inhibitory effect gradually weakened after $30 \mathrm{~h}$, and the bacterial growth began to enter the logarithmic phase. However, when $2 \times$ MIC and $4 \times$ MIC concentrations of daphnetin were added, the bacterial growth could be completely inhibited.

\subsection{Effect on the Integrity of Cell Wall. By separating in-} tracellular enzymes and macromolecular substances, the cell wall plays an important role in maintaining normal growth [26]. AKP is an intracellular enzyme located between the cell wall and membrane, so its activity cannot be detected in the extracellular environment under normal conditions [27]. However, if the cell wall is damaged, it will cause AKP to leak into the extracellular environment, thereby increasing the enzyme activity in the environment. Therefore, the integrity of bacterial cell wall can be evaluated by AKP activity in cell suspension [28]. As presented in Figure 3(a), compared with the control group, the release of AKP was significantly increased in the two bacterial samples treated with daphnetin for $4 \mathrm{~h}$. The AKP activity in the supernatant increased with the increase in daphnetin concentration. After treating with daphnetin, the $\mathrm{OD}_{520}$ value increased from 1.49 to 3.68 in $P$. fluorescens and from 1.47 to 3.02 in S. putrefaciens samples, which suggested that damage to the integrity of the cell wall is probably the primary cause of AKP release into the supernatant. Zheng [29] claimed chlorogenic acid could cause the Escherichia coli cell wall to be destroyed in a short time and had obvious destructive effects. Cao et al. [30] showed that the $\mathrm{OD}_{520}$ value of AKP in Staphylococcus aureus cell suspension increased significantly treated with lactobionic acid for $5 \mathrm{~h}$ compared with the control. Similarly, the results of $\mathrm{He}$ [31] and Ma et al. [32] can also explain this phenomenon. These proved that daphnetin may first act on the cell wall, causing AKP to leak from the cell and cell wall integrity loss by inducing cell wall damage [33].

3.3. Effect on the Integrity of Cell Membrane. Cell membrane can not only maintain the cell environment stable metabolism but also regulate and select substances that enter and leave the cells [26]. Information about the release of cellular components reveals the cytomembrane integrity [34]. When the bacterial membrane is damaged, small ions flow out first, followed by large molecules such as nucleic acids and proteins [35]. Therefore, the leakage of nucleic acids and proteins can reflect the integrity of the membrane. Nucleic acids are one of the most basic substances that allow bacteria to maintain normal life activities. As the concentration of daphnetin increased, the leakage of nucleic acids in bacteria also increased (Figure 3(b)). After $4 \mathrm{~h}$ of treatment with different concentrations of daphnetin $(0 \times, 1 \times, 2 \times$, and $4 \times$ MIC, respectively), the values at $260 \mathrm{~nm}$ were 0.160 , $0.223,0.285$, and 0.318 for P. fluorescens and 0.247, 0.254, 0.282 , and 0.343 for $S$. putrefaciens, respectively. Cui et al. [36] proved that the structure of bacteria was destroyed with the action of clove oil, which resulted in the changes in cell membrane permeability and release of nucleic acids. Zhang 


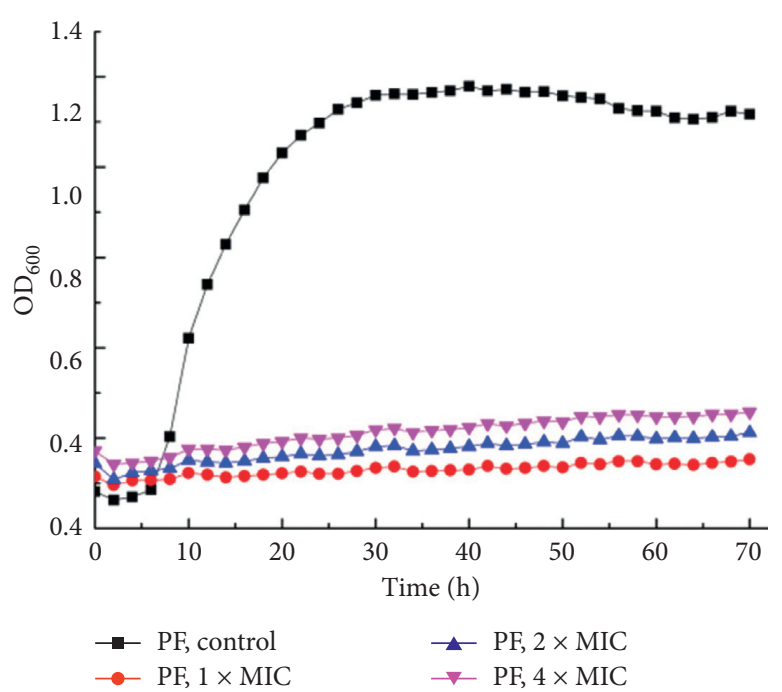

(a)

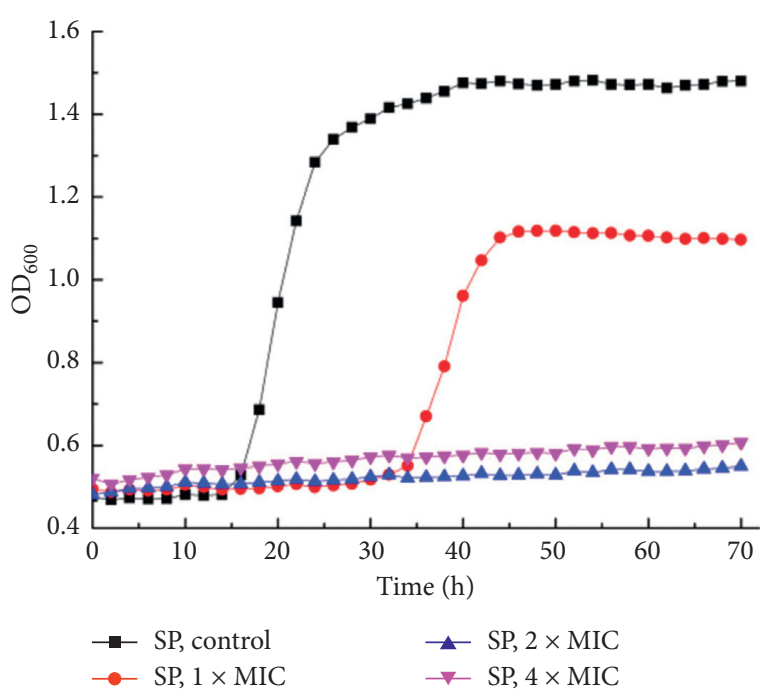

(b)

FIgURE 2: Growth curve of daphnetin against P. fluorescens (a) and S. putrefaciens (b).

et al. [37] demonstrated that the cell membrane integrity of bacteria had been impaired after exposure to cinnamon essential oil. Based on these results, daphnetin could damage P. fluorescens and S. putrefaciens cell membranes and causes nucleic acid leak. Another possible cause is that daphnetin could prevent the synthesis of nucleic acids, and thus, the nucleic acid contents of the treated samples were significantly lower than that of the control [38].

Protein is essential for the life activities of bacteria, it is the material basis and main carrier of life activity, and it is closely related to many life forms. Figure 3(c) shows the protein leakage in the cells or spores of $P$. fluorescens and $S$. putrefaciens treated with different concentrations of daphnetin $(0 \times, 1 \times, 2 \times$, and $4 \times$ MIC, respectively) for $4 \mathrm{~h}$. The addition of daphnetin significantly increased the leakage. Compared with the control, the $\mathrm{OD}_{595}$ of $P$. fluorescens and $S$. putrefaciens treated with $4 \times$ MIC daphnetin for $4 \mathrm{~h}$ was increased by $85.55 \%$ and $93.03 \%$, respectively. Similarly, Meng et al. [39] proved that the essential oil from the leaves of Juniperus rigida destroyed the integrity of Klebsiella pneumoniae membrane, thereby releasing intracellular components such as nucleic acids and proteins. These results indicated that daphnetin could damage the cells and spores of $P$. fluorescens and S. putrefaciens, resulting in leakage of proteins.

3.4. Intracellular Protein Leakage. The bacterial membrane is damaged and treated with the antimicrobial agents, and the protein, small ions, and nucleic acids in the cell will be lost [40]. Therefore, an important indicator of membrane damage is the release of proteins. The change in intracellular protein contents of $P$. fluorescens and S. putrefaciens is shown in Figure 3(d). It can be seen that the protein leakage of $P$. fluorescens and S. putrefaciens increased significantly after $4 \mathrm{~h}$ of daphnetin treatment. The content of intracellular protein decreased from $288.563 \mu \mathrm{g} \cdot \mathrm{mL}^{-1}$ (control) to
$230.043,215.918$, and $197.756 \mu \mathrm{g} \cdot \mathrm{mL}^{-1}(1 \times, 2 \times$, and $4 \times$ MIC) for $P$. fluorescens and from $205.828 \mu \mathrm{g} \cdot \mathrm{mL}^{-1}$ (control) to $159.416,133.183$, and $18.161 \mu \mathrm{g} \cdot \mathrm{mL}^{-1}(1 \times, 2 \times$, and $4 \times$ MIC) for S. putrefaciens, respectively, which indicated that daphnetin changed the cell membrane permeability and caused protein leakage. Our findings were consistent with the results of other researchers. Liu et al. [41] showed that the soluble protein content of the treated samples was lower than that of the control, indicating that these proteins were lost through the damaged cell membrane. Wang et al. [42] found that lactic acid may cause a large amount of protein leakage from Salmonella, E. coli, and Listeria cells. Fei et al. [43] noticed that the antibacterial effect of olive oil polyphenol extract on Cronobacter sakazakii was related to the release of protein. Moreover, He et al. [44] observed that when flavonoids were added to the E. coli strain, bacterial proteins leaked into extracellular suspensions during the detection period. These proved that daphnetin can reduce the cellular protein content by destroying the bacterial membrane and inhibiting its synthesis [45].

3.5. Determination of ATPase Activity. Enzyme, as a biocatalyst, participates in various chemical reactions of biological metabolism and is affected by various factors so that organisms can adapt to changes in external conditions to keep normal life activities [46]. ATP is a glycolysis product in bacterial cell walls and cell membranes. ATPase is one of the main enzymes that promotes the formation and metabolism of ATP [19]. As shown in Figure 3(e), the activity of ATPase decreased when compared with the control group. After $4 \mathrm{~h}$ of exposure to daphnetin, the ATPase content of P. fluorescens and S. putrefaciens was reduced to $2.107 \mathrm{U} \cdot \mathrm{mL}^{-1}$ prot and $0.315 \mathrm{U} \cdot \mathrm{mL}^{-1}$ prot, respectively, which may be due to the destruction of cell membranes and inhibition of ATPase activity by daphnetin leading to the loss of ATP 

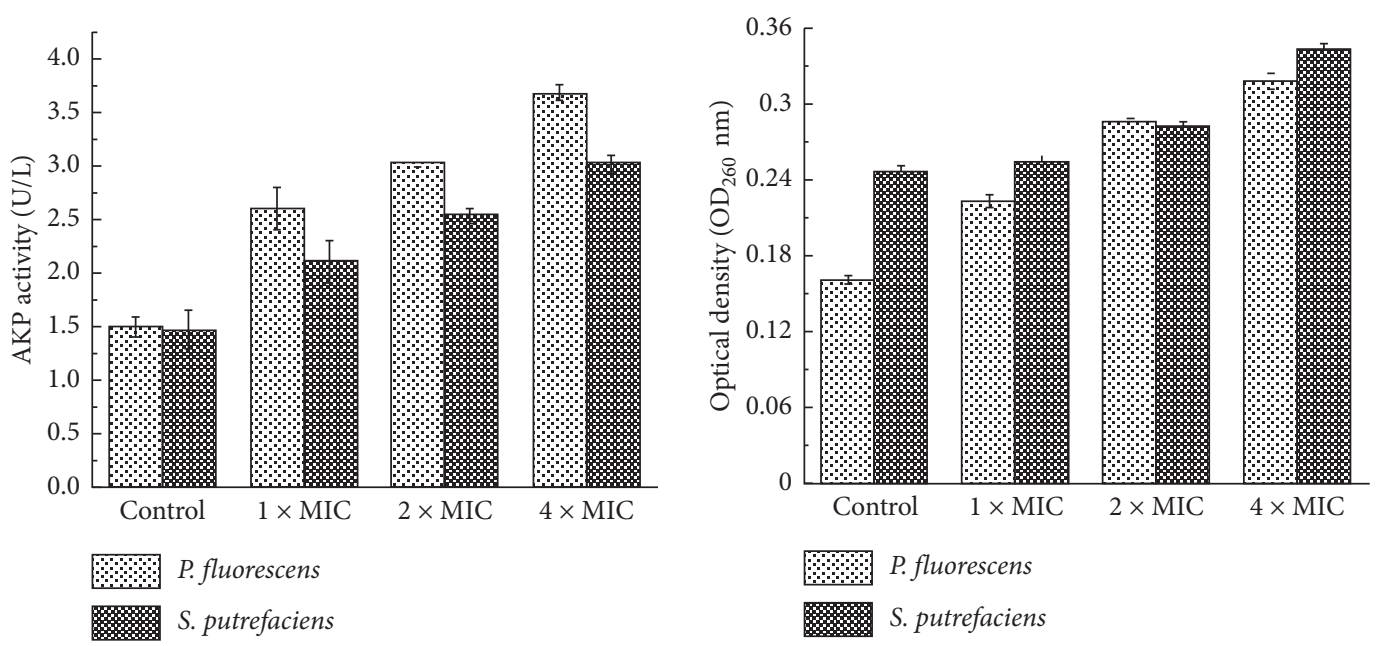

(a)

(b)

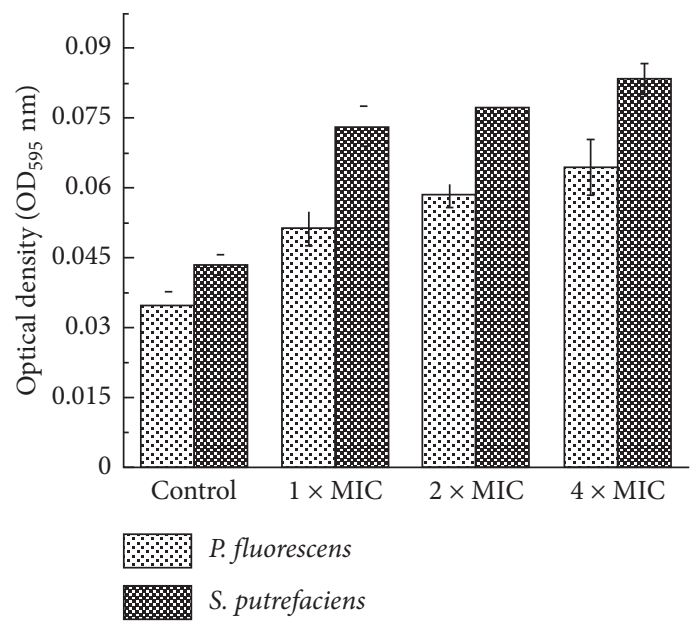

(c)

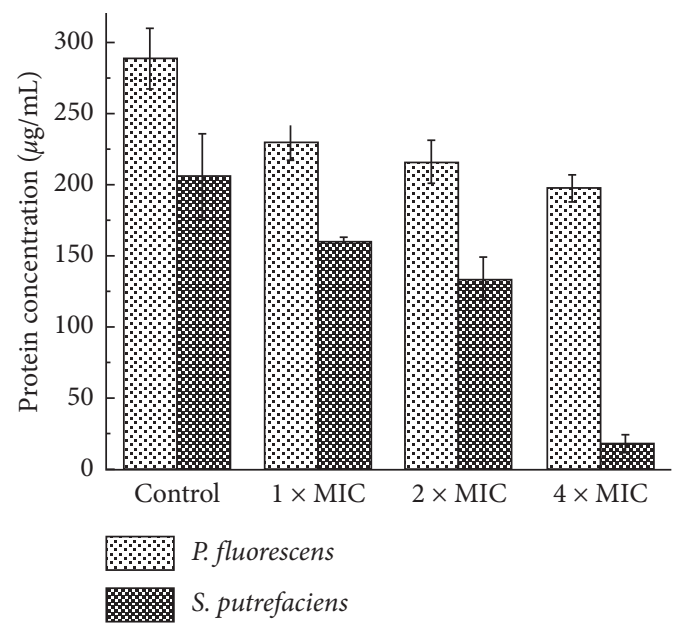

(d)

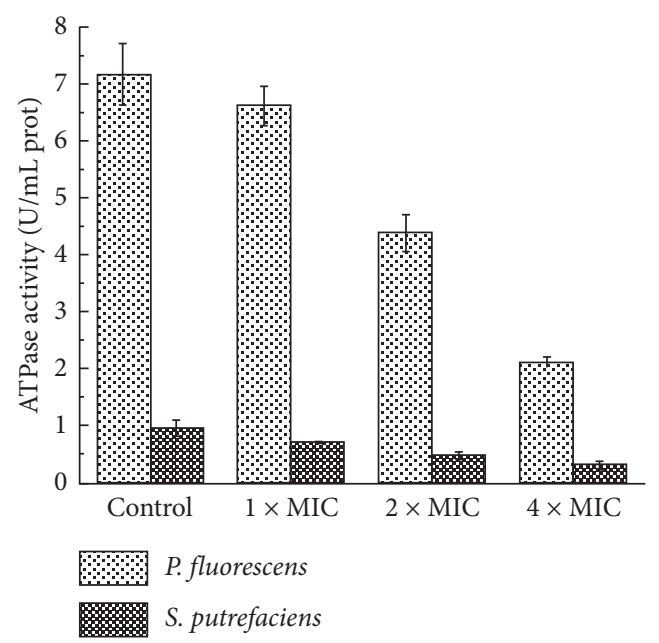

(e)

FIGURE 3: Alkaline phosphatase (AKP) activity (a), leakage of intracellular nucleic acids (b) and intracellular proteins (c), protein leakage (d), and ATPase activity (e) of daphnetin against P. fluorescens and S. putrefaciens.

balance inside and outside the cell. Previous studies considered that the decrease in ATPase level was one of the main factors leading to bacterial cell death [20]. Joung et al. [47] reported that luteolin could inhibit the effect of ATPase in. Moreover, Cai [48] speculated that Polygonum orientale extracts damaged Clavibacter michiganensis subsp. 


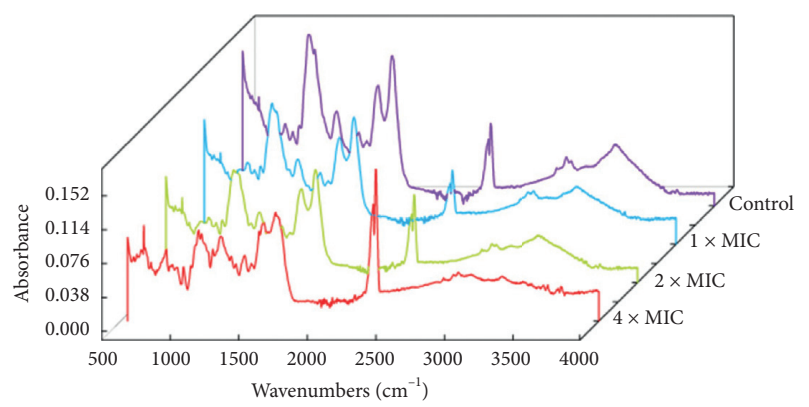

(a)

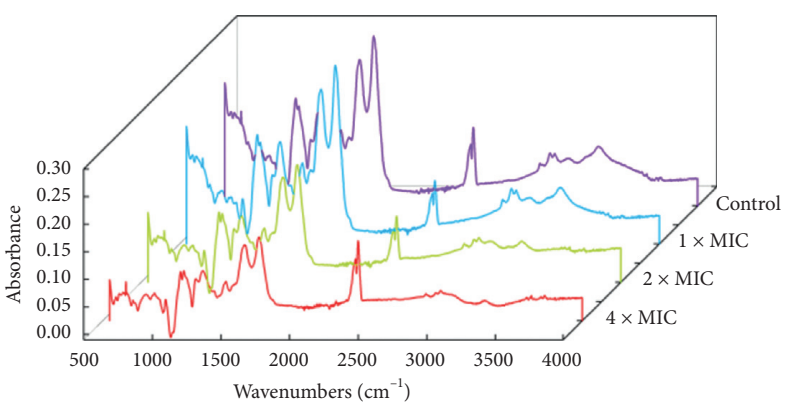

(b)

FIgURE 4: The Fourier transform infrared (FTIR) spectroscopy of P. fluorescens (a) and S. putrefaciens (b) treated with daphnetin.

michiganensis cell membrane and caused the inhibition of ATPase activity in the plasma membrane. Hu et al. [16] revealed that the addition of Litsea cubeba essential oil to MRSA reduced four typical ATPases $\left(\mathrm{Na}^{+} / \mathrm{K}^{+}-\mathrm{ATPase}, \mathrm{Mg}^{2+}-\right.$ ATPase, $\mathrm{Ca}^{2+}$-ATPase, and $\mathrm{Ca}^{2+} / \mathrm{Mg}^{2+}$-ATPase) activity. In addition, Cui et al. [49] showed that the activity of ATPase was related to the energy metabolism carried out by bacteria, and oregano essential oil could reduce the activity of $\mathrm{Na}^{+} / \mathrm{K}^{+}$ATPase, $\mathrm{Mg}^{2+}$-ATPase, and $\mathrm{Ca}^{2+}$-ATPase in MRSA bacteria. These results indicated that one of the main factors leading to bacterial cell death is the reduction in ATPase levels.

3.6. FTIR Spectroscopy. The secondary structure of the biomacromolecule conjugate in the strain was detected by FTIR technology to verify the antibacterial activity of daphnetin against the tested strain. The characteristic absorption bands observed around $3279 \mathrm{~cm}^{-1}, 2924 \mathrm{~cm}^{-1}, 2358 \mathrm{~cm}^{-1}, 1640 \mathrm{~cm}^{-1}$, $1538 \mathrm{~cm}^{-1}, 1231 \mathrm{~cm}^{-1}$, and $1066 \mathrm{~cm}^{-1}$ correspond to the deformation of $\mathrm{OH}$ stretching vibration, $\mathrm{CH}$ stretching vibration, $\mathrm{CN}$ stretching vibration, $\mathrm{CO}$ stretching vibration, proteinamide II, SO stretching vibration, and nucleic acid, respectively $[9,50,51]$. As can be seen from Figure 4(a), the bands of $P$. fluorescens decreased at $1640 \mathrm{~cm}^{-1}$ and $1538 \mathrm{~cm}^{-1}$, meaning that the proteins in the strain leaked into the extracellular environment. At the same time, the band of $1074 \mathrm{~cm}^{-1}$ also dropped, suggesting that the growth of $P$. fluorescens was inhibited due to nucleic acid leakage. As shown in Figure 4(b), the changes in absorption peaks at $3274 \mathrm{~cm}^{-1}$ and $1231 \mathrm{~cm}^{-1}$ indicated that daphnetin disrupted the phospholipid structure on the cell membrane. The decrease of $1633 \mathrm{~cm}^{-1}$ band indicated that the protein leaked into the extracellular environment. Meanwhile, the absorption peak at $1066 \mathrm{~cm}^{-1}$ reduced, indicating that the nucleic acids were leaking, so the growth of $S$. putrefaciens was inhibited. These phenomena are also the same as the findings regarding cell membrane integrity. However, there was no significant difference in other absorption peaks.

3.7. Effect on the Morphology of P. fluorescens and S. putrefaciens Cells. The morphological changes in cells or spores from $P$. fluorescens and $S$. putrefaciens treated with different amounts of daphnetin $(0 \times, 1 \times, 2 \times$, and $4 \times \mathrm{MIC}$, respectively) for $6 \mathrm{~h}$ were observed by SEM. In the control
(Figure 5, A1 and B1), it showed a typical rod-like structure with a flat and complete surface, and the protoplasts in cells were filled and dense with high density. In contrast, the cell structure changed significantly after treatment with different concentrations of daphnetin. The two bacterial cell membrane surfaces at $1 \times$ MIC showed dents and ruffles. When the daphnetin concentration achieved $2 \times$ MIC, the structure of the two bacterial membranes changed noticeably. The cell surface of the two bacteria became twisted, dissolved, and even contracted together. At $4 \times \mathrm{MIC}$, the surface of the two bacterial cells had many pits and wrinkles. These results were also consistent with a previous report [52] and showed SEM changes in S. putrefaciens cells treated with cinnamon oil were damaged; some cells were ruptured, and some were not smooth. Another article reported [53] that, after treatment with rLc-P5L, the SEM images of $P$. fluorescens had similar changes. These results were reminiscent of those reported by Ferreira et al. [54], who found that, after benzyldimethyldodecylammonium chloride treatment, the cell volume of Pseudomonas fluorescens seemed to be rougher, wrinkled, and deformed for the membrane. These phenomena indicated that, after $6 \mathrm{~h}$ of incubation with daphnetin, the cell membranes and cell walls of the bacteria were destroyed to varying degrees. The loss of cell integrity leads to cell destruction and division.

TEM was used to observe the morphological changes in P. fluorescens and S. putrefaciens cells or spores after treatment for $4 \mathrm{~h}$ with different concentrations of daphnetin $(0 \times$ and $4 \times \mathrm{MIC})$, respectively. The surface interactions were studied by TEM, and the leakage of cellular secretions (in the treated cells) in the surrounding medium was found [55]. The control P. fluorescens and S. putrefaciens maintained typical bacterial morphology with clear nuclei, cytoplasm, cell membranes, and cell walls (Figure 6, A1 and B1). Treated P. fluorescens (Figure 6, A2) displayed significant variability. First, the bacterial cell walls and cell membranes were destroyed, lysed, and broken. Secondly, bacterial cytoplasm extravasated, forming a clear cavity. S. putrefaciens after treatment (Figure 6, B2) also showed obvious change in characteristics. The cells were highly deformed, the cell walls ruptured, and the cytoplasm leaked. Similarly, Lee et al. [56] confirmed that SKN has the activity of anti-MRSA, which leads to cell dissolution and leakage of cytoplasmic content by destroying bacterial cell walls and plasma membranes. Chen et al. [57] reported that the strain 

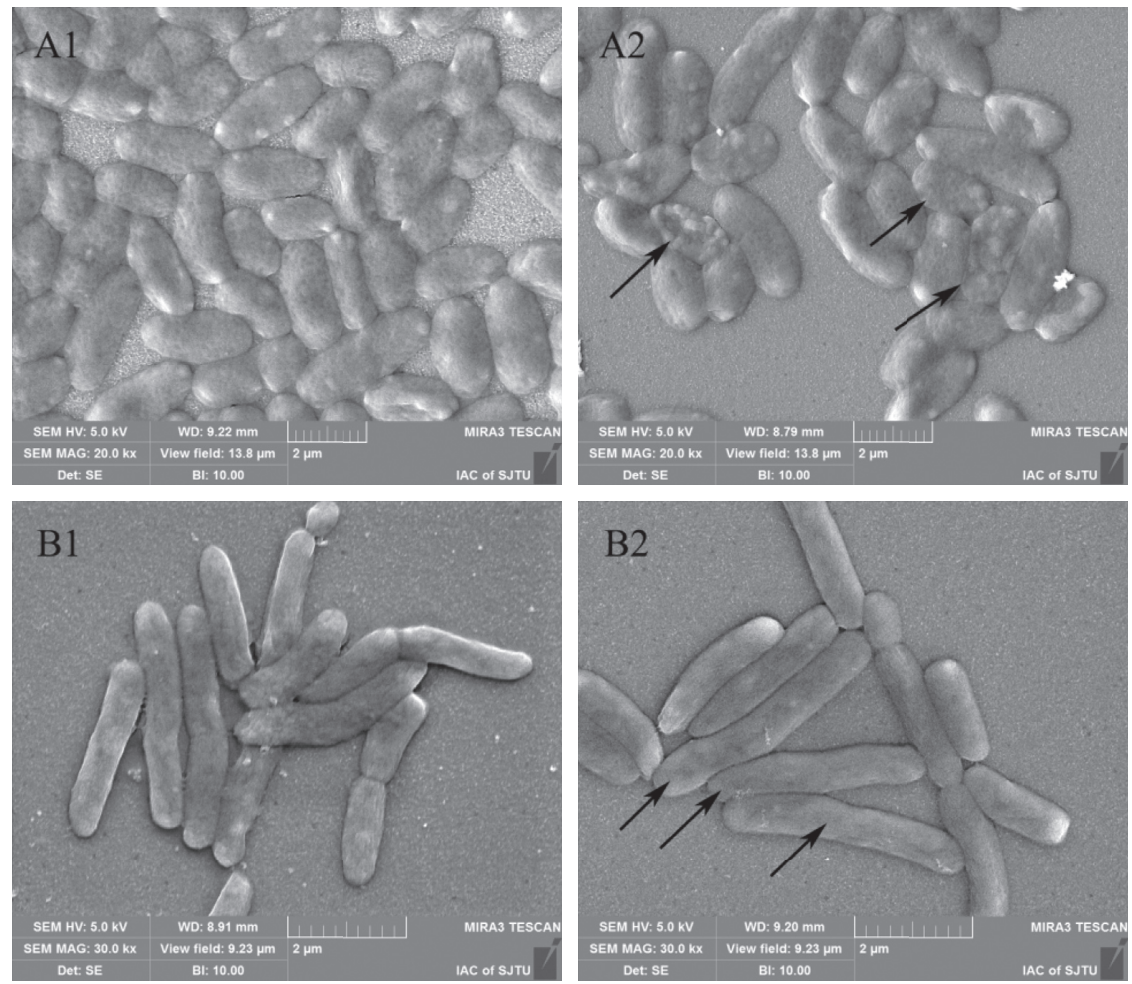

(a)
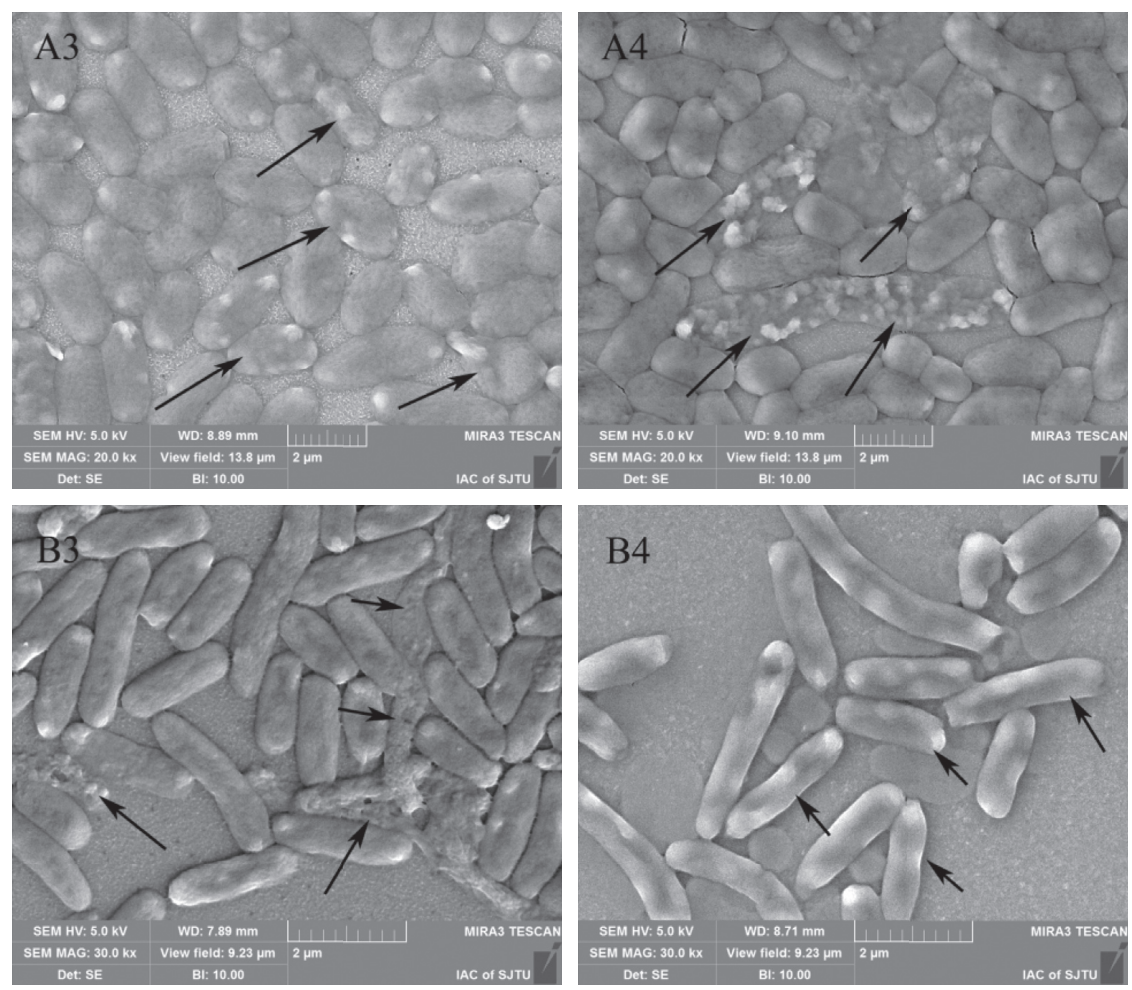

(b)

Figure 5: Scanning electron micrographs of P. fluorescens (a) and S. putrefaciens (b) (A1-B1, control; A2-B2, addition of $1 \times$ MIC daphnetin; A3-B3, addition of $2 \times$ MIC daphnetin; A4-B4, addition of $4 \times$ MIC daphnetin).

cells treated with sugar beet molasses induced the disorder of cell membrane function and showed obvious intracellular damage. Lee and Je [58] showed that the treatment of
S. aureus and E. coli with gallic acid-g-chitosan (I) could promote the outflow of intracellular substances. Wang et al. [59] explained that the cell walls and membranes of S. aureus 

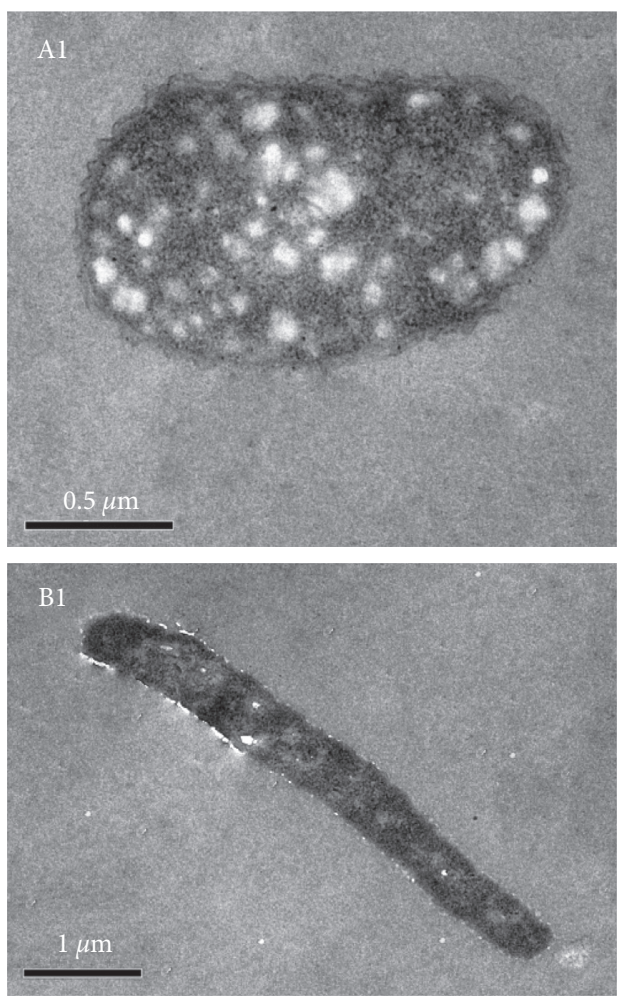

(a)
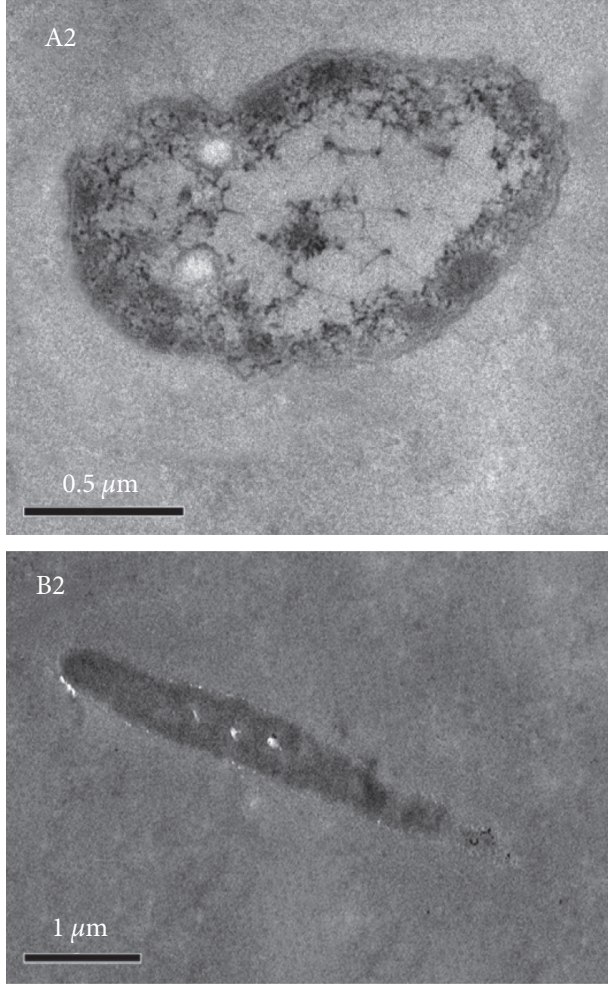

(b)

Figure 6: Transmission electron micrographs of $P$. fluorescens (a) and S. putrefaciens (b) (A1-B1, control; A2-B2, addition of $4 \times$ MIC daphnetin).

and E. coli treated with SE (the synergistic combination between alcohol extracts from the Chimonanthus salicifolius $\mathrm{S}$. Yi et al. leaves and streptomycin) were broken and dissolved, and the cytoplasm of bacteria leaked out, forming a clear cavity. These phenomena indicated that the addition of polyphenols may interfere with the division of bacterial cells, causing the cells to change from a typical long rod shape to a short rod shape or coccus shape [60]. Obviously, according to the results, the cells of the strain treated with daphnetin will suffer significant internal damage by inducing cell membrane dysfunction [57].

\section{Conclusions}

This research reported the antibacterial activity and mechanism of daphnetin on $P$. fluorescens and S. putrefaciens. The MIC of daphnetin acting on $P$. fluorescens was $0.16 \mathrm{mg} \cdot \mathrm{mL}^{-1}$ and that of $S$. putrefaciens was $0.08 \mathrm{mg} \cdot \mathrm{mL}^{-1}$. Daphnetin can destroy the cell wall and membrane integrity of $P$. fluorescens and $S$. putrefaciens, which causes nucleic acid and protein leakage and affects intracellular AKP and ATPase activities. SEM and TEM results showed that daphnetin induced alterations in the morphology and caused the leakage of intracellular contents in bacterial cells. The FTIR spectroscopy of $P$. fluorescens and $S$. putrefaciens indicted daphnetin destroyed the phospholipid structure on the membrane and the nucleic acid and protein leakage resulting in the growth inhibition of $P$. fluorescens and S. putrefaciens. Overall, our results indicate that daphnetin is a promising natural preservative used as a potential substitute for synthetic preservatives in food industry providing a viable strategy for enhancing microbial inactivation.

\section{Data Availability}

The data used to support the findings of this study are available from the corresponding author upon request.

\section{Conflicts of Interest}

The authors declare that there are no conflicts of interest regarding the publication of this paper.

\section{Acknowledgments}

This research was funded by the China Agriculture Research System (CARS-47), Shanghai Science and Technology Key Project on Agriculture from Shanghai Municipal Agricultural Commission (2019-02-08-00-10-F01143), National Key Research and Development Program (2016YFD0400106), and Shanghai Science and Technology Commission Platform Capacity Construction Project (19DZ2284000).

\section{References}

[1] J. Mei, X. Ma, and J. Xie, "Review on natural preservatives for extending fish shelf life," Foods, vol. 8, no. 10, p. 490, 2019. 
[2] S. Khalili Tilami and S. Sampels, "Nutritional value of fish: lipids, proteins, vitamins, and minerals," Reviews in Fisheries Science \& Aquaculture, vol. 26, no. 2, pp. 243-253, 2018.

[3] K. H. Jackson, J. M. Polreis, N. L. Tintle, P. M. Kris-Etherton, and W. S. Harris, "Association of reported fish intake and supplementation status with the omega-3 index," Prostaglandins, Leukotrienes and Essential Fatty Acids, vol. 142, pp. 4-10, 2019.

[4] G. Comi, "Chapter 8 - spoilage of meat and fish," in The Microbiological Quality of Food, A. Bevilacqua, M. R. Corbo, and M. Sinigaglia, Eds., pp. 179-210, Woodhead Publishing, Cambridge, UK, 2017.

[5] A. Marchese, R. Barbieri, E. Coppo et al., "Antimicrobial activity of eugenol and essential oils containing eugenol: a mechanistic viewpoint," Critical Reviews in Microbiology, vol. 43, no. 6, pp. 668-689, 2017.

[6] G. Bono, C. O. R. Okpala, S. Vitale et al., "Effects of different ozonized slurry-ice treatments and superchilling storage $\left(-1^{\circ} \mathrm{C}\right)$ on microbial spoilage of two important pelagic fish species," Food Science \& Nutrition, vol. 5, no. 6, pp. 1049-1056, 2017.

[7] F. F. Parlapani, G. I. Verdos, S. A. Haroutounian, and I. S. Boziaris, "The dynamics of pseudomonas and volatilome during the spoilage of gutted sea bream stored at $2^{\circ} \mathrm{C}$," Food Control, vol. 55, pp. 257-265, 2015.

[8] Q. Q. Zhou, "Preservative effects of gelatin active coating containing eugenol and higher $\mathrm{CO}_{2}$ concentration modified atmosphere packaging on Chinese sea bass (lateolabrax maculatus) during superchilling $\left(-0.9^{\circ} \mathrm{C}\right)$ storage," Molecules, vol. 25, no. 4, p. 17, 2020.

[9] S. Y. Fang, "Antimicrobial carvacrol incorporated in flaxseed gum-sodium alginate active films to improve the quality attributes of Chinese sea bass (lateolabrax maculatus) during cold storage," Molecules, vol. 24, no. 18, p. 17, 2019.

[10] J. Liu, "Daphnetin protects against cerebral ischemia/reperfusion injury in mice via inhibition of TLR4/NF- $\kappa \mathrm{B}$ signaling pathway," BioMed Research International, vol. 2016, Article ID 2816056, 6 pages, 2016.

[11] B. Song, "Immunosuppressive activity of daphnetin, one of coumarin derivatives is mediated through suppression of NF$\kappa \mathrm{B}$ and NFAT signaling pathways in mouse T cells," PLoS One, vol. 9, no. 5, 2014.

[12] W. Zhang, S. Zhuo, L. He et al., "Daphnetin prevents methicillin-resistant Staphylococcus aureus infection by inducing autophagic response," International Immunopharmacology, vol. 72, pp. 195-203, 2019.

[13] L. Jurd, J. Corse, A. D. King, H. Bayne, and K. Mihara, "Antimicrobial properties of 6, 7-dihydroxy-, 7, 8-dihydroxy-, 6-hydroxy- and 8-hydroxycoumarins," Phytochemistry, vol. 10, no. 12, pp. 2971-2974, 1971.

[14] F. Cottigli, "Antimicrobial evaluation of coumarins and flavonoids from the stems of L," Phytomedicine, vol. 8, no. 4, pp. 302-305, 2001.

[15] K. Xu, L. Guo, H. Bu, and H. Wang, "Daphnetin inhibits high glucose-induced extracellular matrix accumulation, oxidative stress and inflammation in human glomerular mesangial cells," Journal of Pharmacological Sciences, vol. 139, no. 2, pp. 91-97, 2019.

[16] W. Hu, C. Li, J. Dai, H. Cui, and L. Lin, "Antibacterial activity and mechanism of Litsea cubeba essential oil against methicillin-resistant Staphylococcus aureus (MRSA)," Industrial Crops and Products, vol. 130, pp. 34-41, 2019.
[17] C. Shi, "Antimicrobial activity and possible mechanism of action of citral against cronobacter sakazakii," PLoS One, vol. 11, no. 7, 2016.

[18] R. Cai, M. Zhang, L. Cui et al., "Antibacterial activity and mechanism of thymol against Alicyclobacillus acidoterrestris vegetative cells and spores," LWT-Food Science and Technology, vol. 105, pp. 377-384, 2019.

[19] L. Lin, Y. Gu, C. Li, S. Vittayapadung, and H. Cui, "Antibacterial mechanism of $\varepsilon$-Poly-lysine against listeria monocytogenes and its application on cheese," Food Control, vol. 91, pp. 76-84, 2018.

[20] H. Cui, M. Bai, Y. Sun, M. A.-S. Abdel-Samie, and L. Lin, "Antibacterial activity and mechanism of chuzhou chrysanthemum essential oil," Journal of Functional Foods, vol. 48, pp. 159-166, 2018.

[21] L. Lin, X. Mao, Y. Sun, and H. Cui, “Antibacterial mechanism of artemisinin/beta-cyclodextrins against methicillin-resistant Staphylococcus aureus (MRSA)," Microbial Pathogenesis, vol. 118, pp. 66-73, 2018.

[22] R. Su, T. Li, D. Fan et al., "The inhibition mechanism of $\epsilon$ -polylysine against Bacillus cereus emerging in surimi gel during refrigerated storage," Journal of the Science of Food and Agriculture, vol. 99, no. 6, pp. 2922-2930, 2019.

[23] Z. Tan, T. Bo, F. Guo, J. Cui, and S. Jia, "Effects of $\varepsilon$-poly-l-lysine on the cell wall of Saccharomyces cerevisiae and its involved antimicrobial mechanism," International Journal of Biological Macromolecules, vol. 118, pp. 2230-2236, 2018.

[24] H. Li, Y. Gao, C. Li, G. Ma, Y. Shang, and Y. Sun, "A comparative study of the antibacterial mechanisms of silver ion and silver nanoparticles by Fourier transform infrared spectroscopy," Vibrational Spectroscopy, vol. 85, pp. 112-121, 2016.

[25] L. Yang, W. Ding, Y. Xu et al., "New insights into the antibacterial activity of hydroxycoumarins against ralstonia solanacearum," Molecules, vol. 21, no. 4, p. 468, 2016.

[26] N. Zhang, W. Lan, Q. Wang, X. Sun, and J. Xie, “Antibacterial mechanism of ginkgo biloba leaf extract when applied to shewanella putrefaciens and saprophytic staphylococcus," Aquaculture and Fisheries, vol. 3, no. 4, pp. 163-169, 2018.

[27] W. Lan, N. Zhang, S. Liu, M. Chen, and J. Xie, " $\varepsilon$-Polylysine inhibits Shewanella putrefaciens with membrane disruption and cell damage," Molecules, vol. 24, no. 20, p. 3727, 2019.

[28] F. Wang, F. Wei, C. Song et al., "Dodartia orientalis L. essential oil exerts antibacterial activity by mechanisms of disrupting cell structure and resisting biofilm," Industrial Crops and Products, vol. 109, pp. 358-366, 2017.

[29] Y. Zheng, "Extrication process of chlorogenic acid in crofton weed and antibacterial mechanism of chlorogenic acid on Escherichia coli," Journal of Environmental Biology, vol. 37, no. 5, p. 1049, 2016.

[30] J. Cao, H. Fu, L. Gao, and Y. Zheng, "Antibacterial activity and mechanism of lactobionic acid against Staphylococcus aureus," Folia Microbiologica, vol. 64, no. 6, pp. 899-906, 2019.

[31] N. He, "Antibacterial mechanism of chelerythrine isolated from root of toddalia asiatica (linn) lam," Bmc Complementary and Alternative Medicine, vol. 18, p. 9, 2018.

[32] C. Ma, N. He, Y. Zhao, D. Xia, J. Wei, and W. Kang, "Antimicrobial mechanism of hydroquinone," Applied Biochemistry and Biotechnology, vol. 189, no. 4, pp. 1291-1303, 2019.

[33] M. Diao, D. Qi, M. Xu et al., "Antibacterial activity and mechanism of monolauroyl-galactosylglycerol against bacillus cereus," Food Control, vol. 85, pp. 339-344, 2018. 
[34] S. Shen, T. Zhang, Y. Yuan, S. Lin, J. Xu, and H. Ye, "Effects of cinnamaldehyde on Escherichia coli and Staphylococcus aureus membrane," Food Control, vol. 47, pp. 196-202, 2015.

[35] D. Xu, L. Sun, C. Li, Y. Wang, and R. Ye, "Inhibitory effect of glucose oxidase from Bacillus sp. CAMT22370 on the quality deterioration of Pacific white shrimp during cold storage," LWT-Food Science and Technology, vol. 92, pp. 339-346, 2018.

[36] H. Cui, C. Zhang, C. Li, and L. Lin, "Antimicrobial mechanism of clove oil on listeria monocytogenes," Food Control, vol. 94, pp. 140-146, 2018.

[37] Y. Zhang, X. Liu, Y. Wang, P. Jiang, and S. Quek, “Antibacterial activity and mechanism of cinnamon essential oil against Escherichia coli and Staphylococcus aureus," Food Control, vol. 59, pp. 282-289, 2016.

[38] L. Zhao, H. Zhang, T. Hao, and S. Li, "In vitro antibacterial activities and mechanism of sugar fatty acid esters against five food-related bacteria," Food Chemistry, vol. 187, pp. 370-377, 2015.

[39] X. Meng, D. Li, D. Zhou, D. Wang, Q. Liu, and S. Fan, "Chemical composition, antibacterial activity and related mechanism of the essential oil from the leaves of juniperus rigida sieb. et zucc against Klebsiella pneumoniae," Journal of Ethnopharmacology, vol. 194, pp. 698-705, 2016.

[40] S. Kang, F. Kong, X. Shi et al., "Antibacterial activity and mechanism of lactobionic acid against pseudomonas fluorescens and methicillin-resistant Staphylococcus aureus and its application on whole milk," Food Control, vol. 108, p. 106876, 2020.

[41] D. Liu, S. Meng, Z. Xiang, N. He, and G. Yang, “Antimicrobial mechanism of reaction products of morus notabilis (mulberry) polyphenol oxidases and chlorogenic acid," Phytochemistry, vol. 163, pp. 1-10, 2019.

[42] C. Wang, T. Chang, H. Yang, and M. Cui, "Antibacterial mechanism of lactic acid on physiological and morphological properties of salmonella enteritidis, Escherichia coli and listeria monocytogenes," Food Control, vol. 47, pp. 231-236, 2015.

[43] P. Fei, M. A. Ali, S. Gong et al., "Antimicrobial activity and mechanism of action of olive oil polyphenols extract against cronobacter sakazakii," Food Control, vol. 94, pp. 289-294, 2018.

[44] M. He, T. Wu, S. Pan, and X. Xu, "Antimicrobial mechanism of flavonoids against Escherichia coli ATCC 25922 by model membrane study," Applied Surface Science, vol. 305, pp. 515-521, 2014.

[45] X.-h. Sun, T.-t. Zhou, C.-h. Wei et al., "Antibacterial effect and mechanism of anthocyanin rich Chinese wild blueberry extract on various foodborne pathogens," Food Control, vol. 94, pp. 155-161, 2018.

[46] X. Lv, H. Ma, M. Sun et al., "A novel bacteriocin DY4-2 produced by Lactobacillus plantarum from cutlassfish and its application as bio-preservative for the control of Pseudomonas fluorescens in fresh turbot (Scophthalmus maximus) fillets," Food Control, vol. 89, pp. 22-31, 2018.

[47] D.-K. Joung, Y.-S. Lee, S.-H. Han et al., "Potentiating activity of luteolin on membrane permeabilizing agent and ATPase inhibitor against methicillin-resistant Staphylococcus aureus," Asian Pacific Journal of Tropical Medicine, vol. 9, no. 1, pp. 19-22, 2016.

[48] J. Cai, "Antibacterial activity of polygonum orientale extracts against clavibacter michiganensis subsp. michiganensis, the agent of bacterial canker of tomato disease," Brazilian Archives of Biology and Technology, vol. 62, no. 4, 2019.
[49] H. Cui, C. Zhang, C. Li, and L. Lin, "Antibacterial mechanism of oregano essential oil," Industrial Crops and Products, vol. 139, Article ID 111498, 2019.

[50] S. Liang, Q. Dang, C. Liu et al., "Characterization and antibacterial mechanism of poly (aminoethyl) modified chitin synthesized via a facile one-step pathway," Carbohydrate Polymers, vol. 195, pp. 275-287, 2018.

[51] W. Zhang, P. K. Chu, J. Ji et al., "Plasma surface modification of poly vinyl chloride for improvement of antibacterial properties," Biomaterials, vol. 27, no. 1, pp. 44-51, 2006.

[52] F. Lyu, Y.-l. Hong, J.-h. Cai et al., "Antimicrobial effect and mechanism of cinnamon oil and gamma radiation on Shewanella putrefaciens," Journal of Food Science and Technology, vol. 55, no. 9, pp. 3353-3361, 2018.

[53] Y. Pan, L.-b. Zheng, Y. Mao et al., "The antibacterial activity and mechanism analysis of piscidin 5 like from larimichthys crocea," Developmental \& Comparative Immunology, vol. 92, pp. 43-49, 2019.

[54] C. Ferreira, A. M. Pereira, M. C. Pereira, L. F. Melo, and M. Simoes, "Physiological changes induced by the quaternary ammonium compound benzyldimethyldodecylammonium chloride on pseudomonas fluorescens," Journal of Antimicrobial Chemotherapy, vol. 66, no. 5, pp. 1036-1043, 2011.

[55] Z.-Y. Guo, "Antibacterial effects of leaf extract of Nandina domestica and the underlined mechanism," Evidence-Based Complementary and Alternative Medicine, vol. 2018, Article ID 8298151, 9 pages, 2018.

[56] Y. S. Lee, "The mechanism underlying the antibacterial activity of shikonin against methicillin-resistant Staphylococcus aureus," Evidence-Based Complementary and Alternative Medicine, vol. 2015, p. 9, Article ID 520578, 2015.

[57] M. Chen, Z. Zhao, H. Meng, and S. Yu, "The antibiotic activity and mechanisms of sugar beet (beta vulgaris) molasses polyphenols against selected food-borne pathogens," LWT Food Science and Technology, vol. 82, pp. 354-360, 2017.

[58] D.-S. Lee and J.-Y. Je, "Gallic acid-grafted-chitosan inhibits foodborne pathogens by a membrane damage mechanism," Journal of Agricultural and Food Chemistry, vol. 61, no. 26, pp. 6574-6579, 2013.

[59] N. Wang, X. Liu, J. Li et al., "Antibacterial mechanism of the synergistic combination between streptomycin and alcohol extracts from the chimonanthus salicifolius S. Y. Hu. leaves," Journal of Ethnopharmacology, vol. 250, p. 112467, 2020.

[60] S.-M. Yi, J.-L. Zhu, L.-L. Fu, and J.-R. Li, "Tea polyphenols inhibit Pseudomonas aeruginosa through damage to the cell membrane," International Journal of Food Microbiology, vol. 144, no. 1, pp. 111-117, 2010. 